\section{Rediscovery of Darkfield Dispersion Staining while Building a Universal Student Microscope}

Theodore M. Clarke, Metallurgical Failure Analysis Consultant tclarke@ligtel.com

My first universal student microscope, shown in Figure 1, began life as a Monolux microscope from the 1960's. Its development into a universal student microscope began when my wife

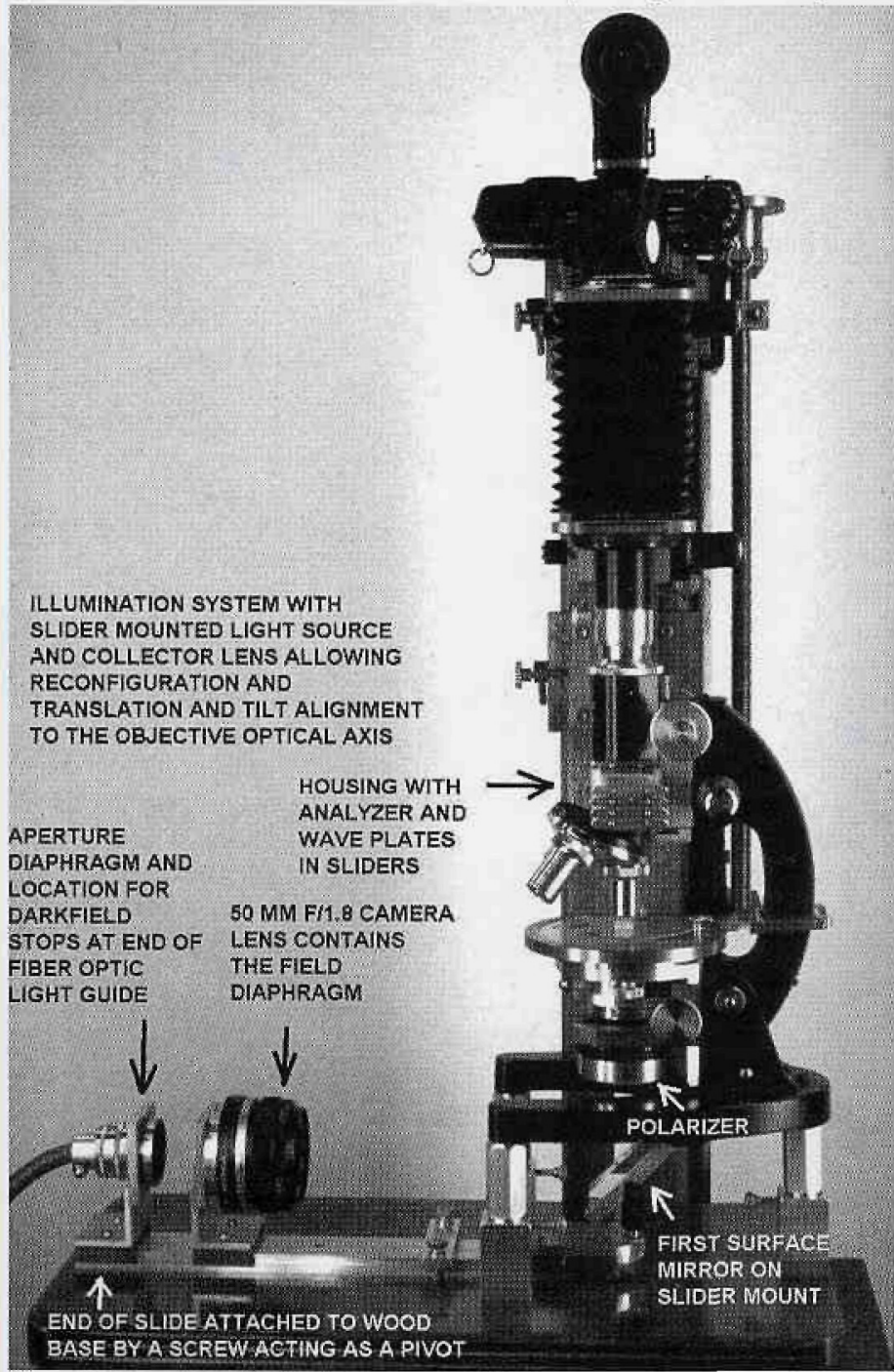

Figure 1-View of the student microscope configured for working with transmitted polarized light.

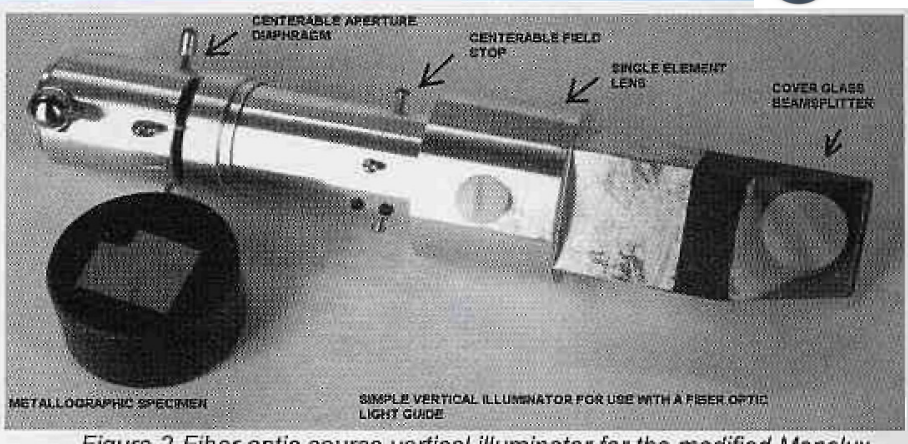

Figure 2-Fiber optic source vertical illuminator for the modified Monolux student microscope.

wanted a polarized light microscope with the ability to photograph microscopic crystals under a cover glass for their artistic value. My background as a metallurgist was with the reflected light metallurgical microscope. I have also designed and built vertical illuminators for brightfield illumination of complete metallographic specimens using a fiber optic light guide end as the light source with lens configurations giving an imaged field diaphragm and an illumination aperture diaphragm imaged in the aperture of the macro lens. The cost of a new polarized light microscope for my wife was beyond our means. Consequently I began the design modifications for the Monolux to give it the capability of Koehler illumination with high intensity illumination from an external illuminator using the end of a fiber optic light guide as the light source as I had done previously with the vertical illuminators. The components of this system are slide mounted, permitting longitudinal variations in their positions for the objectives being used. This system also has the capability for translating and tilting the beam from the mirror for centering of both the image of the field diaphragm and the image of the aperture diaphragm. The typical $5 X$ objective is not designed for Koehler illumination because it lacks a field lens, present in $5 X$ metallurgical objectives. The noses of these objectives usually have an extension with an aperture at the end of the nose to block out excess light, which would be scattered by the edges of the lens elements. The proper location for the image of the light source is then in the aperture of the nose extension. My system has this capability, called Koehler-Clarke illumination by John Delly, who was my adviser for this project. The eyepiece in my modified Monolux is in a centerable drawtube with a threaded end for a macro lens, which was salvaged from a slide copier. This macro lens is focused through an open position in the turret or on the rear focal plane of an objective, when it is used as a Bertrand lens. A very precise rotating stage was made with a special journal bearing design. The upper and lower disks of the stage have mating outer, horizontal annular flats. A central hollow taper extension on bottom of the upper disk mates with a female socket in the centerable lower disk. The flats and tapers are fitted to make simultaneous contact separated only by a thin film of oil.
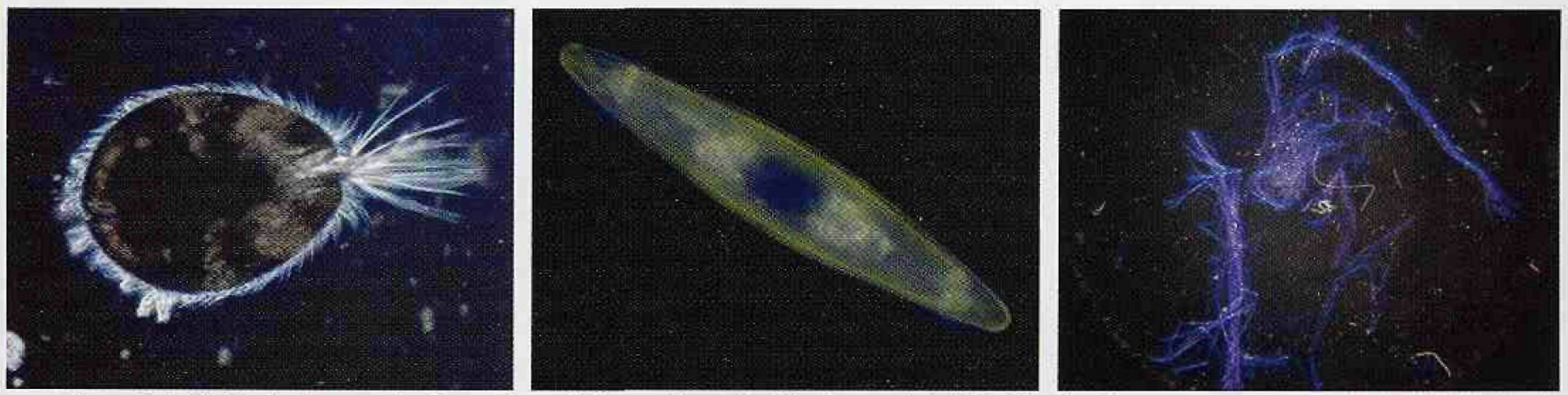

Figure 3, Left-Photomicrograph of an ostracod taken with a 5 X objective and darkfield illumination.

Figure 4, Center-Photomicrograph of a diatom taken with a $40 \mathrm{X}$ objective and darkfield illumination.

Figure 5, Right-Photomacrograph showing Chrysotile asbestos with plane polarized critical darkfield illumination. 


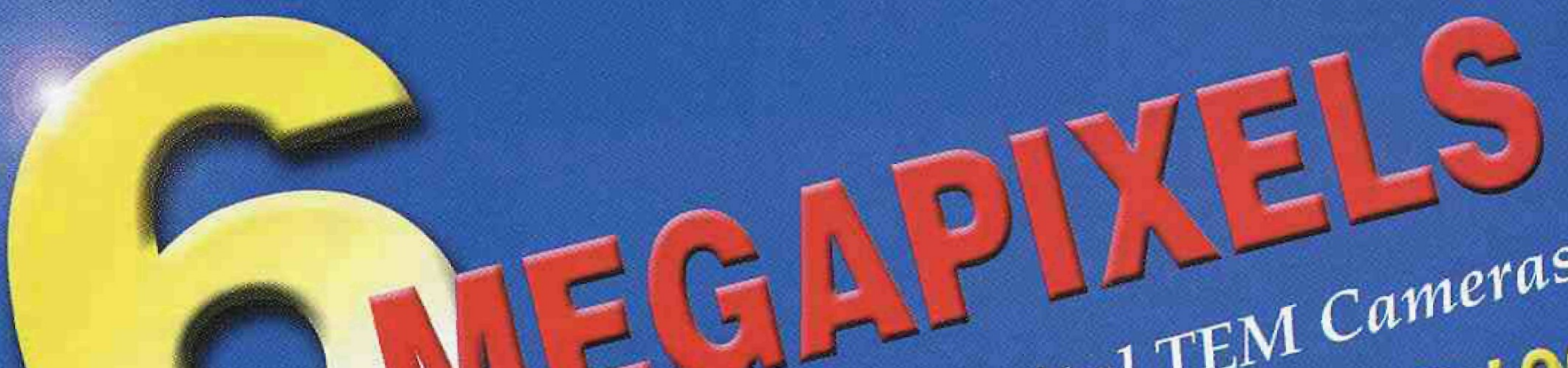

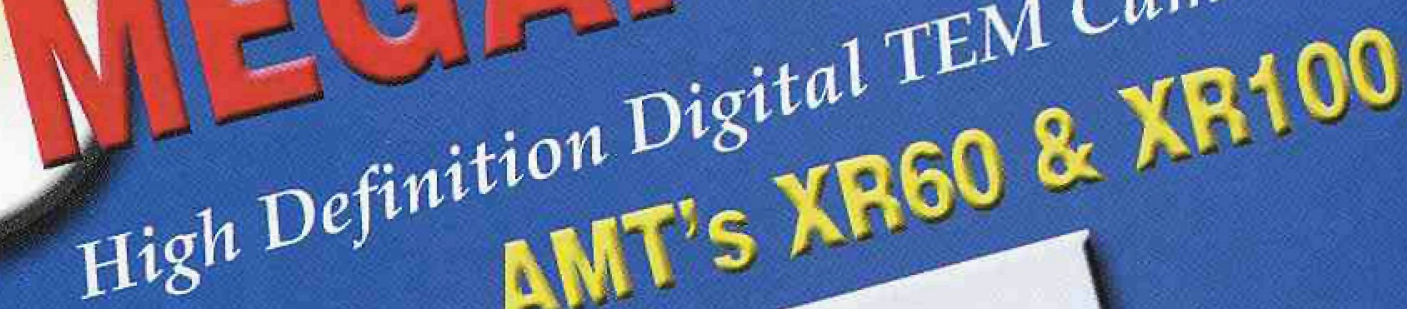

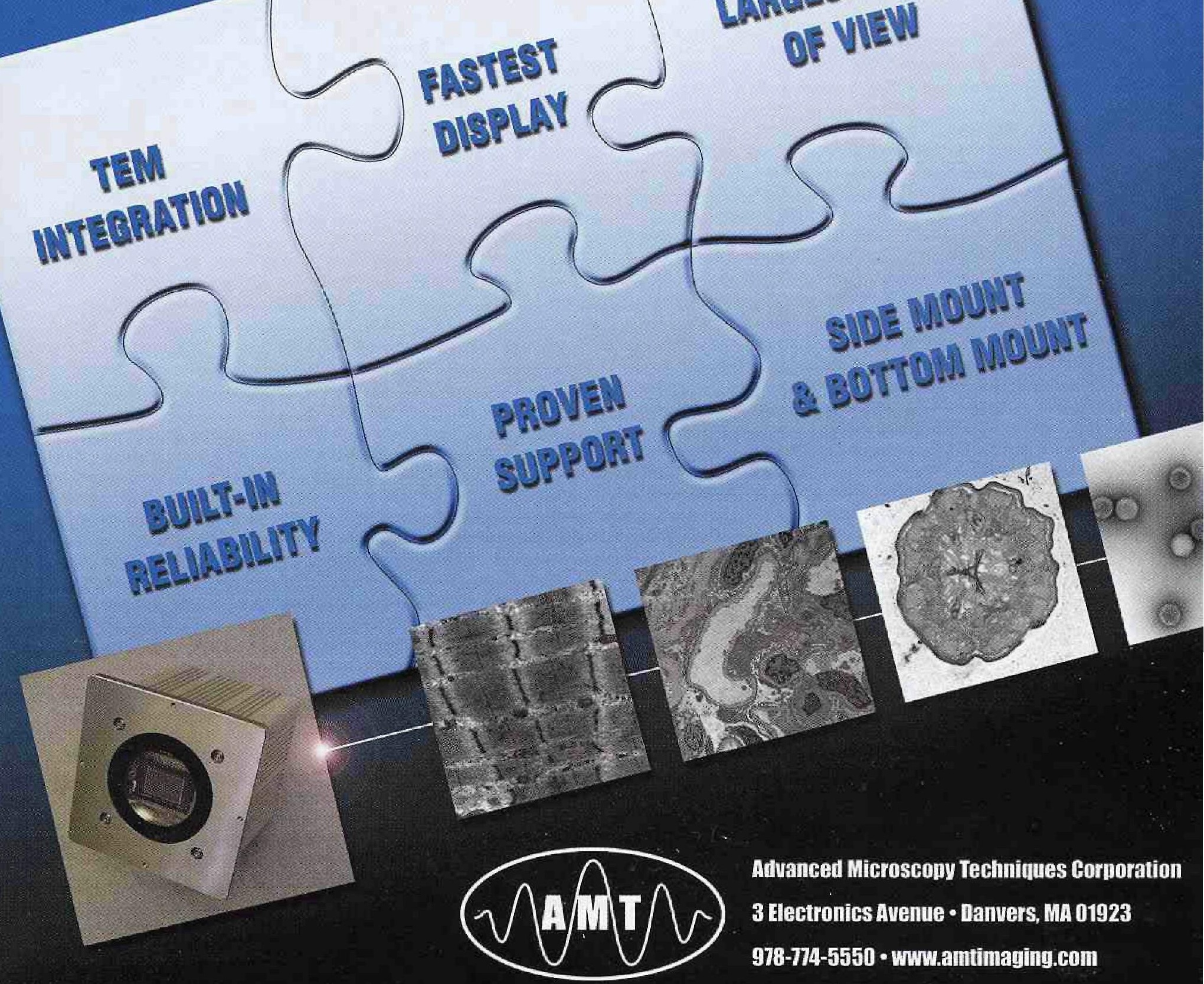




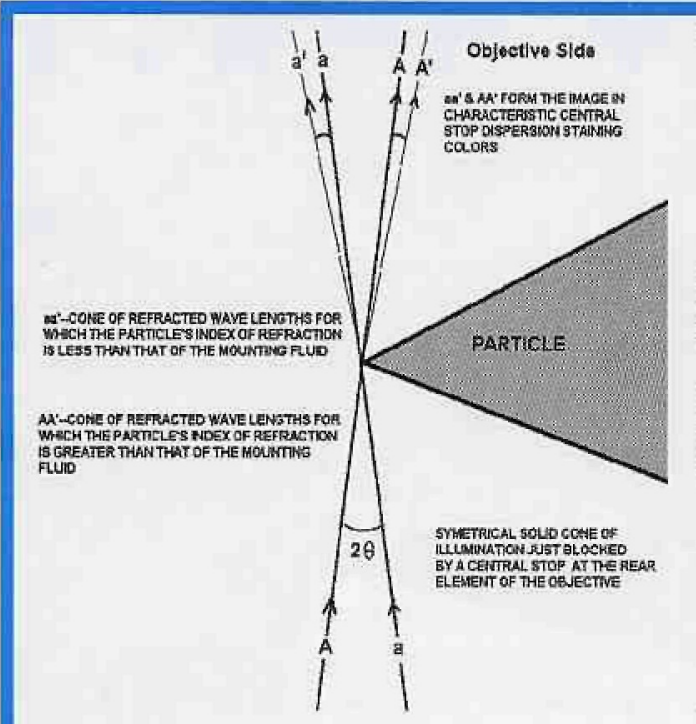

Central Stop Dispersion staining

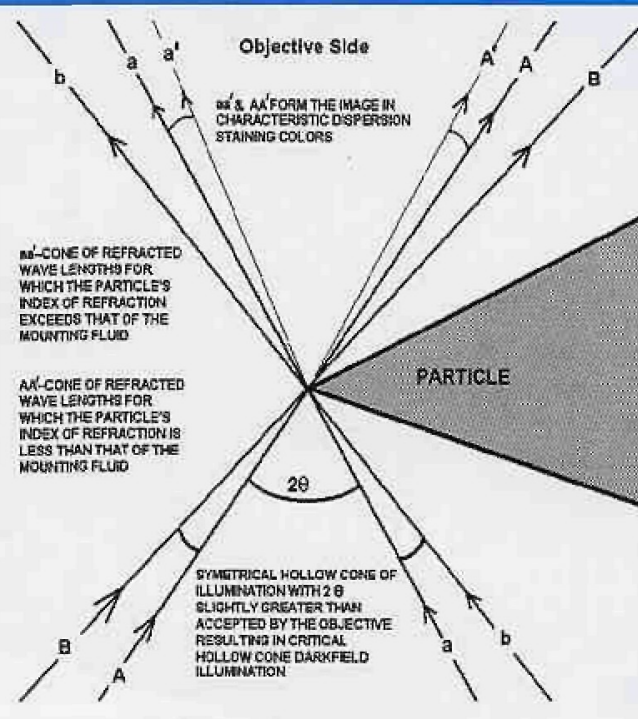

Critical Darkfieid Dispersion Staining

capabilities at the McCrone Research Institute that a discovery was made that plane polarized darkfield resulted in the characteristic colors of central stop dispersion staining with mineral samples in the appropriate matching but higher dispersion of index medium. This is the topic for the remainder of this article. A more complete description of this system is given in my article: Clarke, T. M. "Building an Affordable Universal Student Microscope": The Microscope 2000,48, 19-39. I will be glad to provide by e-mail any additional information needed.

The Chrysotile asbestos in the slide \#57 from the McCrone Research Institute Reference Slide Set is shown in plane polarized darkfield in Figure 5 in a $10 \mathrm{~mm}$ field diameter that was imaged with the drawtube mounted macro lens. The colors of the fibers are the characteristic central stop dispersion staining.

Figure 6-Ray diagrams illustrating both central stop and critical darkfield dispersion

A housing was added near the objective turret to contain sliders for the wave plates and the analyzer, all punched from polymer film. These sliders are removed and the vertical illuminator is inserted for converting to vertical illumination needed for metallography, thus resulting in a universal student microscope. The end of the $1 / 4$ fiber optic light guide is used as the light source in the vertical illuminator shown in Figure 2, with no diffuser needed for either reflected or transmitted bright field illumination. One of the early applications of this microscope was for examining live organisms in pond water. Darkfield illumination gave the highest contrast for that application. Locating the stop at the light source was found to be best, especially when the top elements of the homemade condenser were removed for use with the $5 X$ objective and the macro lens. Figures $3 \& 4$ show some examples taken with the $5 X$ and $40 X$ objectives and darkfield illumination. The stops were sized so they were just large enough in diameter to block any ring of brightfield visible at the rear of the objective, where an image of the stop is also formed. It was during a demonstration of this microscope's

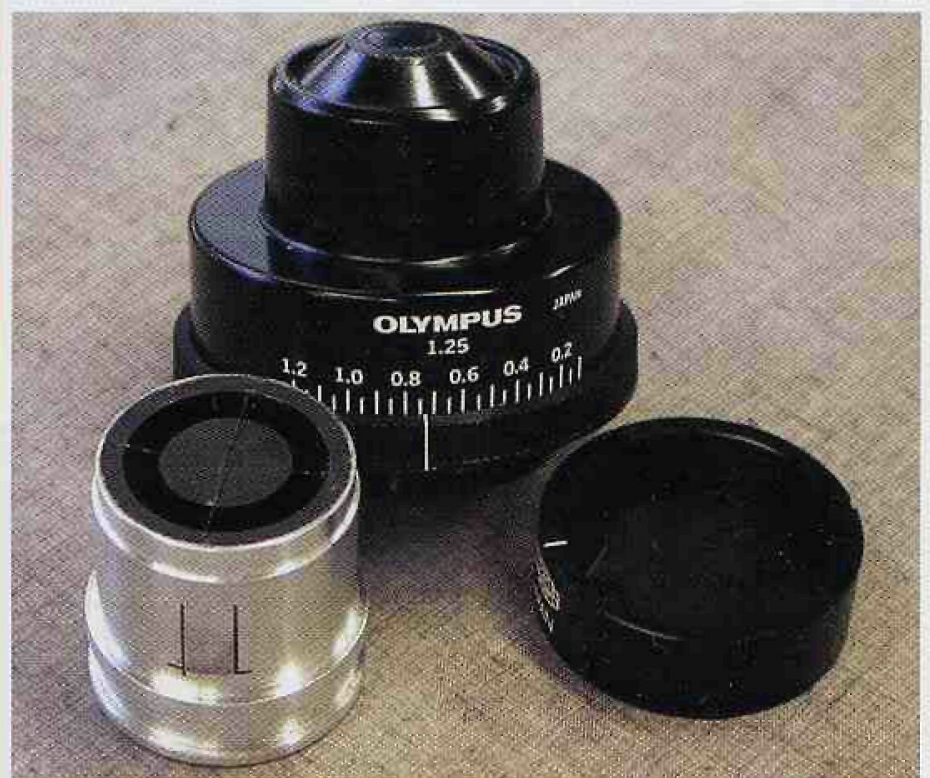

Figure 7-Photograph of the Olympus Abbe condenser and the insert for critical darkfield dispersion staining with the 40X 0.65 NA Olympus objective.

staining colors for Chrysotile in $1.550 \mathrm{HD}$ index mountant, but obtained with what I call critical darkfield dispersion staining. Figure 6 contains ray diagrams illustrating how the dispersion colors arise for both dispersion staining methods. A modified $10 \mathrm{X}$ objective with a typically $2 \mathrm{~mm}$ diameter central stop nearly in contact with the rear element is used for central stop dispersion staining. I added this capability to a Monolux 10X objective for comparison of the central stop method with critical darkfield dispersion staining using the same objective and without removing the central stop. The central stop images show intense diffraction fringes characteristic of this method which are not present in the critical darkfield images. The visible diffraction fringes are the result of the low NA of both the illuminating and image forming rays and seriously reduce the spatial resolution of the 0.25 NA objective. The critical darkfield dispersion staining method works even with an objective NA of 1.25 , provided that the particles are well dispersed so they are not touching. My second student microscope, a modified LOMO Biolam student microscope is used with the 1.40 NA LOMO condenser for critical darkfield dispersion staining at and above an objective NA of 1.0. Use of this condenser, corrected to be aplanatic when used dry, with oil to the bottom of the slide introduces severe spherical aberration so that the field diaphragm can no longer be imaged. This modified LOMO Biolam microscope was used by Tony Havics of ph2 for his Inter/Micro2002 presentation. He demonstrated that small fibers of Chrysotile asbestos could be identified by critical darkfield dispersion staining in powdered wallboard core material (mainly gypsum) to which was added $0.5 \%$ and $0.1 \%$ by weight of short range (Calibra deposit type) Chrysotile asbestos. He also measured the spatial resolution using the phase contrast HSE/NPL resolution test slide. He was able to resolve Block \#5 (0.44 micrometer line width) using the LOMO 0.65 NA40X objective and Block \#2 (0.77 micrometer line width) using the Monolux $10 \mathrm{X}$ objective, both with critical darkfield illumination. None of the line patterns were resolved with the same $10 \mathrm{X}$ objective and central stop dispersion staining illumination. I subsequently repeated Tony's test results using a test slide loaned by Peter Cooke.

Tony Havics found that critical darkfield dispersion staining was first discovered by Nelson Dodge of B\&L and published in: Dodge, Nelson B, "The Darkfield Color Immersion Method" The American Mineralogist 33 (9\&10): 541-549, 1948. It is unfortunate 
DIGITAL IIIIAGIIIG

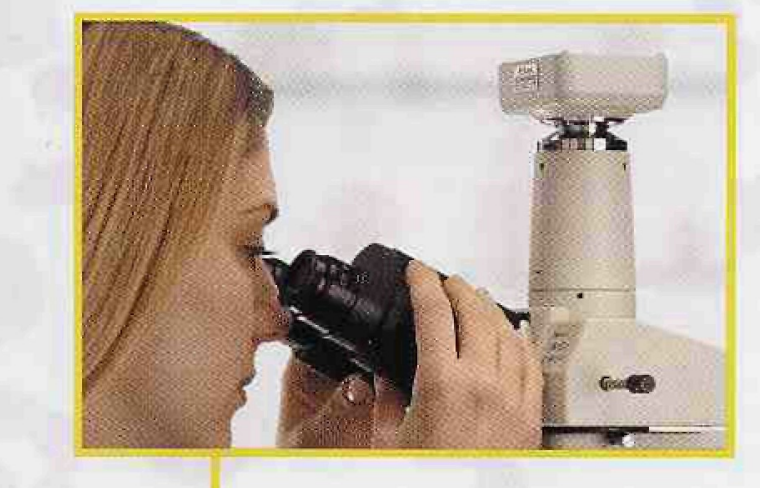

\section{The job's \\ easier when}

everyone

sees things

the same way.
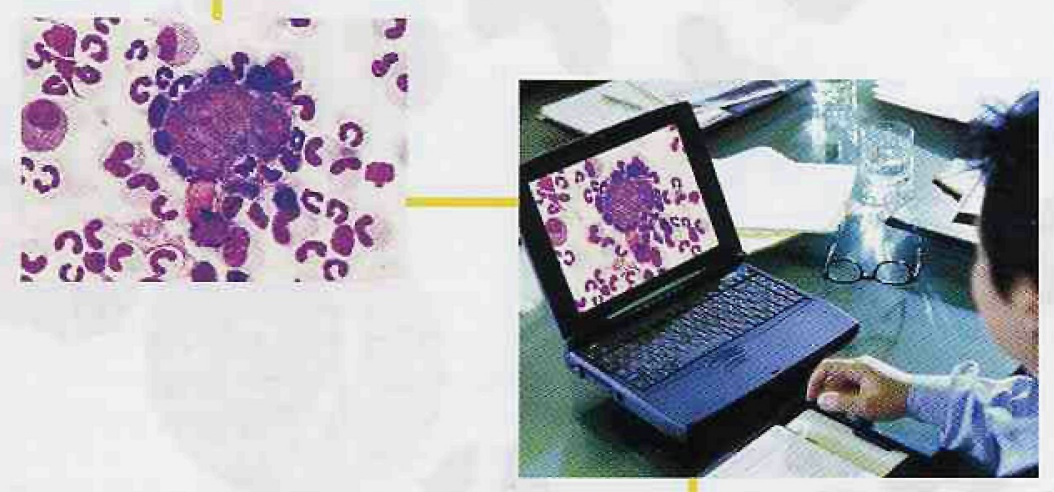

Now, any image can be shared by everyone anywhere with Nikon's Dn100 network camera.

Here's a terrific way to capture, share and archive your valuable images. Simply plug the Nikon Dn 100 Digital Camera directly into a network. That's all. It's trouble free, cost effective and there's no need for a PC or special soffware.

The DN 100 enables simultaneous viewing of images by many people in different locations at megapixel resolution. So, if you need others to see what you see, then this is the perfect digital camera for your microscope.

Features and benefits that make the DN 100 so innovative:

- Users in remote locations can control the camera through a slandard Internet browser.

- The camera is a plafform independent network applianceconnects directly to a LAN or WAN.

- Versatile command options include image zoom, auto scaling, draw on screen, and split screen comparison of live and stored images.

To find out more about this highly advanced network camera, call 1-800-52-NIKON, ext. 394 or visit www. nikonusa.com

In Canada, call 1-866-99-NIKON.

Visit MicroscopyU at www.nikonusa.com to learn more about digital imaging.
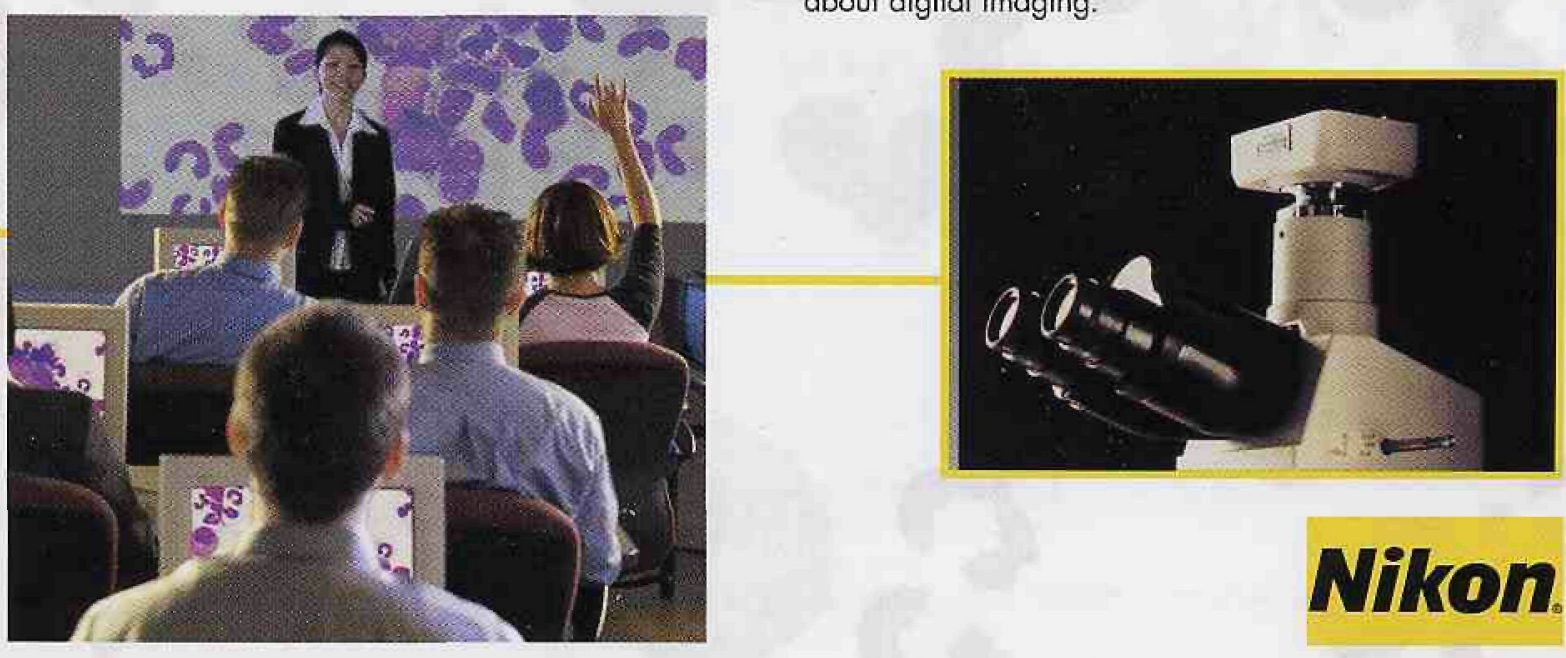


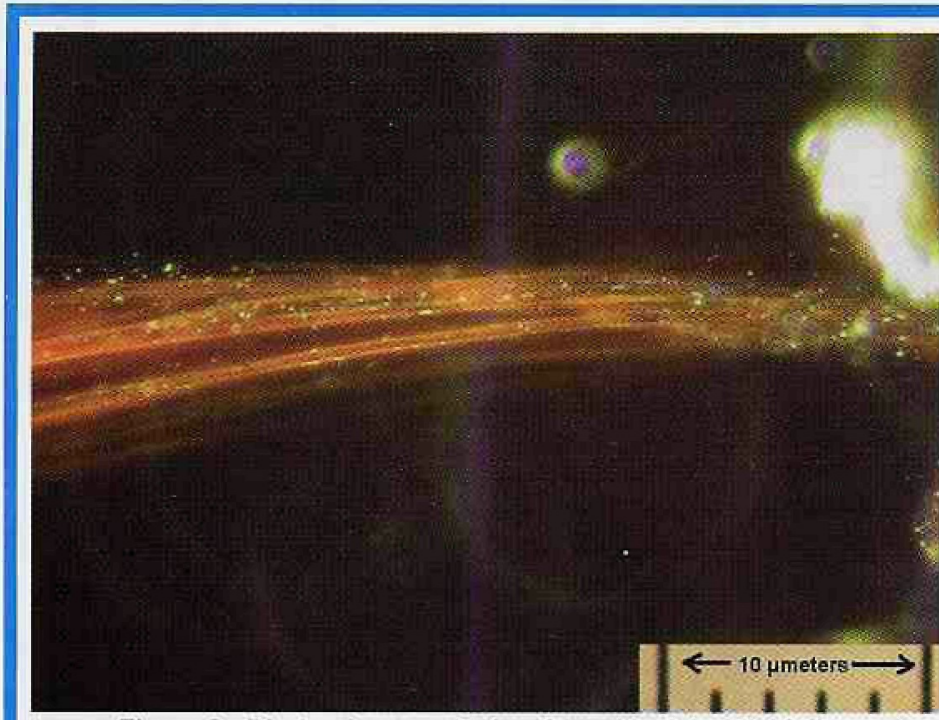

Figure 8 - Photomicrogragh showing critical darkfield dispersion staining of Amosite asbestos using an Olympus $\mathrm{BH} 2$ microscope. that his discovery did not lead to commercial availability of microscopes with this capability and adoption of the method by particle microscopists.

From a real-world application standpoint, I was pleased that Peter M. Cooke (pmcooke@earthlink.net), a leading instructor of microscopy courses both nationally and internationally, has found darkfield dispersion staining to be an important adjunct to the curriculum in his advanced asbestos identification courses. In particular, using the adapters students can resolve finer asbestos fibers at much higher magnifications than they routinely use in their laboratories.

I found that I could add critical darkfield dispersion capability for the $40 \mathrm{X}$ Olympus objectives with condenser inserts I made for the 1.25 NA Abbe condensers used in his courses. One of these darkfield stop inserts is shown in Figure 7 . Koehler brightfield illumination with crossed polars is used to locate the fibers and then the insert is slid into the condenser. Since the Abbe condenser has severe spherical aberration at higher NA, the condenser height must be subsequently adjusted to illuminate the particles with darkfield illumination. This adjustment is not necessary with the aplanatic condenser on my modified Biolam when using the LOMO $40 \mathrm{X}$ objective. There is an additional advantage with the modified Biolam of being able to improve the darkfield contrast by centering the particle and closing the field diaphragm around it. The aperture diaphragm should be adjusted to let in a very thin, hollow cone of illumination just above the acceptance angle of the objective for maximum dispersion staining contrast. Figure 8 shows a bundle of Amosite asbestos fibers photographed by Peter using his Olympus $\mathrm{BH} 2$ and one of the inserts. Note the foreign particle on the right, which strongly scatters white light and reduces the darkfield contrast. Other causes of loss of good darkfield are a smeared film on the slide or cover glass, bubbles in the mountant, and dirt on the condenser lens elements. I far prefer using a condenser that is at least aplanatic for critical darkfield in place of the inexpensive Abbe condensers. The darkfield stops, critically sized for each objective, should be in a centerable wheel in the condenser, as is common practice for phase contrast condensers. Such a condenser should be very useful also for microbiology applications. My student microscopes are now suited only for serious students of light microscopy and researchers on a very limited budget.

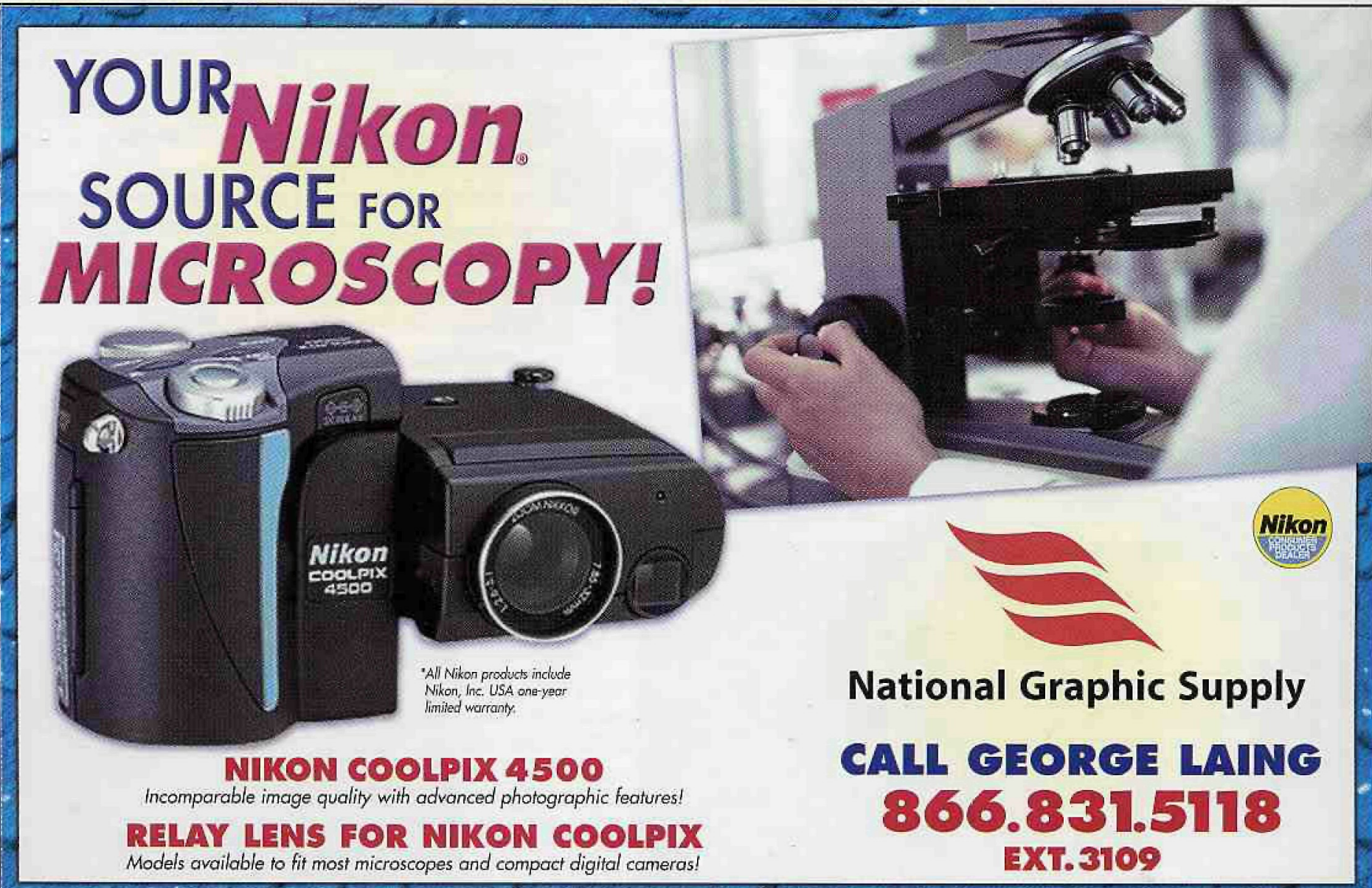

